This document is the Accepted Manuscript version of a Published Work that appeared in final form in British Journal of Nursing, copyright (C) MA Healthcare, after peer review and technical editing by the publisher. To access the final edited and published work see https://doi.org/10.12968/bjon.2019.28.2.84 


\title{
Diagnosis and management of a urinary tract infection (UTI)
}

Linda Collins, PhD

\begin{abstract}
A urinary tract infection (UTI) is a common bacterial infection and is the leading reason for treatment in primary care within the United Kingdom. Women are more frequently affected with a UTI than men and the debilitating condition often presents itself with painful urination, urinary frequency, the inability to start urinating, the sensation to suddenly urinate and many other symptoms. Assessment and identification of the infection is crucial and nurses have a fundamental role when assessing symptoms, examining a specimen of urine and promptly reporting the findings.
\end{abstract}

\section{Introduction}

A urinary tract infection (UTI) is a common bacterial invasion of the urinary tract, and is the leading reason for treatment in primary care within the United Kingdom (NICE 2013). Recent studies have shown that women are more frequently affected with a UTI than men, requiring prudent antibiotic treatment (Asma, Vicky et al. 2018). It has been reported that a UTI is a common medical condition accounting for 7 to 8 million clinic visits per year (Robinson, Giarenis et al. 2015). The urinary tract is constantly exposed to bacteria from the exterior environment, particularly because of the anatomical placement of the urethra, in the vicinity of the rectum for females (Okragla, Szychowska et al. 2014). A UTI is a debilitating condition in severe cases and can produce the onset of painful urination (Dysuria), urinary frequency, the inability to start urinating (hesitancy) and the sensation to suddenly urinate (urgency) (Bono and Reygaert 2018). 
The lower urinary tract consists of the ureters, the bladder, the trigone and the urethra (Watson 2011). The bladder has three distinctive layers, the outer tissue layer which is known as serosa; the middle smooth layer is called the detrusor muscle which is responsible for the contractions that set off the sensation to void and the innermost lining layer is called the urothelium and comprises of transitional cell epithelium that provides an elastic barrier that is impervious to urine (Patel and Chapple 2008).

Mysorekar and Hultgren (2006) report that an infection of the lower urinary tract occurs when bacteria invades the urethra, migrates to the urothelium and colonises the cells of epithelium of the bladder. When the superficial bladder cells have been invaded, the uropathogens rapidly begin to replicate inside the bladder cells and form intracellular communities, also known as intracellular colonisation. Intracellular pathogens such as Escherichia Coli hijack bladder cells which line the urothelium, allowing pathogens to reach an appropriate intracellular position for their survival and replication (Panek, El Alaoui et al. 2014). The process of intracellular colonisation has been related to the development of urinary biofilms, which is the process in which infected bladder cells form a protective barrier, hindering the suppression of infected cell multiplication and promoting the progression of the UTI (Flores-Mireles, Walker et al. 2015). The multiplication of biofilms in the bladder cells hinder the bladder function triggering lower urinary tract symptoms (LUTS) such as urinary hesitancy, reduced urinary stream, bladder pain and incomplete bladder emptying also known as urinary retention (Rosen and Klumpp 2014).

\section{Symptoms and assessment}

When patients report lower urinary tract symptoms (LUTS), in most cases this is indicative of a sudden or worsening onset of a UTI also known as an acute flare, which presents its self as storage, voiding and incontinence symptoms (Haylen, De Ridder et al. 2010). An assessment of symptoms using a validated tool such as the female lower urinary tract symptoms questionnaire (FLUTS) (Jackson, Donovan et al. 1996) and the quality of life questionnaire for urinary incontinence (I-QOL) (Wagner, Patrick et al. 1996), are systematic methods for measuring and assessing the presence of urinary frequency, urgency, urinary incontinence, voiding symptoms and bladder pain (Al Buheissi, Khasriya et al. 2008), and the impact it has 
on a patients quality of life. It is good practice for nurses to use a validated assessment tool, but depending on the clinical settings such as hospital, community or outpatient departments, assessment tools may have been developed based upon the concept of the FLUTS and I-QOL questionnaires.

\section{Urine samples and diagnostic testing}

A UTI is often diagnosed by examining a urine sample. In nursing practice, there are two main methods for obtaining a urine specimen which is the clean-catch midstream urine method (MSU), capturing the middle part of the urinary stream and the catheter specimen method (CSU), which is the insertion of a thin hollow tube, along the urethra and into the bladder to obtain a specimen (Dougherty, Lister et al. 2015). The selection of the collection method depends upon the patient's clinical case, but more commonly a MSU is requested for testing.

A dipstick urinalysis is generally used in clinical practice, as it is a rapid inexpensive diagnostic test which is used in conjunction with or in place of a urine culture (Huysal, Budak et al. 2013). The dipstick urinalysis distinctively measures the markers of pyuria and bacteriuria, the two diagnostic factors often associated with a UTI (Turner, Beigi et al. 2014). When interpreting a dipstick urinalysis, pyuria is the measurement of urinary leukocytes and bacteriuria is the presence of nitrites (Pappas 1991). Not all dipstick urinalysis tests detect the presence of leukocytes and nitrites, but identifying any one of these signs increases the positive predictive value of the urinalysis (Raza-Khan, Kenton et al. 2006). Although it is a standard method for routinely screening for the presence of infection, the dipstick has been discredited due to its inability to sensitively detect the presence of a UTI in comparison to urine microscopy (Khasriya, Khan et al. 2010).

Urine microscopy has been used to identify urinary leukocytes since the early 1890s. Cuthbert Dukes (1928) introduced another method of assessing urine using a counting chamber to enumerate the white cells in a fresh unspun specimen. From then onwards newer studies investigated the use of urinary microscopy for identifying bacteriuria, as an alternative to relying on urine cultures (Hallstrom, Hallstrom et al. 1975, Vickers, Ahmad et al. 1991, Hiraoka, Hida et al. 1993). Urine microscopy is also used to detect the presence of 
haematuria (Yeoh, Lai et al. 2013) and uroepithelial cells which originate from the bladder wall (Horsley, Malone-Lee et al. 2013, Khasriya, Sathiananthamoorthy et al. 2013). More recent studies advocate the use of light microscopy as a standard screening practice for detecting pyuria and bacteriuria in males and females (Sorrentino, Cartwright et al. 2014, Gill, Kang et al. 2018). Nurses in some clinical settings are undertaking urinary microscopy however; adequate training is the initial important step for developing the skill.

Urine cultures have been recommended as the gold standard for diagnosing the pathogens that are responsible for a UTI (Davies and Lewis 2004), and although nurses are not trained to perform urine cultures, the ability to promptly send a urine specimen for microbiological testing, culture and antibiotic sensitivity is an important task. Bacterial infections recognised as the most common etiological cause of a UTI, and accounts for 75 to $90 \%$ diagnosed cases of a UTI in both outpatient and inpatient settings (Kashef, Djavid et al. 2010). Evidence has shown that a bacterial infection of the bladder can disrupt the function of the urothelium, a protective lining of the bladder, triggering an inflammatory response that causes the parasitised transitional cells to migrate to the surface of the bladder, exfoliate and pass out as part of the urinary stream (Anderson, Palermo et al. 2003, Reigstad, Hultgren et al. 2007, Khasriya, Sathiananthamoorthy et al. 2013). Nowadays, these exfoliated urothelial cells, detected on microscopy, are regarded as important diagnostic markers of infection. Some methods of analysis would interpret these cells as a contaminants (Collier, Matjiu et al. 2013) but novel methods of cell identification have shown these cells to originate from the bladder and are a reflection of the infection (Horsley, Malone-Lee et al. 2013).

\section{Nursing management of a UTI}

Nurses have the ability to assess and identify the presence of UTI with appropriate training. When a UTI has been identified, nurses should refer the patients to a registered medical doctor or a nurse prescriber who will then proceed with treatment options. Acute and chronic UTI are often managed by a physician who prescribes antibiotics and Methenamine, an effective bladder antiseptic for preventing the progression of a UTI (Lee, Bhuta et al. 2012). Treatment cessation is usually permitted when there is a reduction in LUTS and there is a visible reduction urinary pyuria (Swamy, Barcella et al. 2018). 
It is important that nurses encourage patients to report the initial onset of bladder symptoms, as this often helps to prevent the progression of the infection with an early intervention. The fundamental role of the nurse when managing a UTI is to conduct a comprehensive symptom assessment and educating the patient on symptom characteristics. Symptom assessments using validated questionnaires is an integral part of urology practice and is a structured method to distinguish duration of symptoms, triggers and exacerbating factors (Betschart, Abt et al. 2018). Understanding the symptom characteristics will support nurses when educating the patient on the importance of early reporting of symptoms. Examining a specimen of urine will determine whether an infection is present and promptly reporting the findings will hasten the facilitation of the treatment process (Nik-Ahd, Lenore Ackerman et al. 2018).

\section{Conclusion}

A UTI is frequently diagnosed as a common debilitating condition, with women being more affected than men. Understanding the anatomy of the bladder provides a clearer perspective of how bacterial invades the bladder causing the infection. The assessment and identification of the infection is crucial and nurses have a fundamental role when assessing symptoms, examining a specimen of urine and promptly reporting the findings. 
Al Buheissi, S., R. Khasriya, B. H. Maraj and J. Malone-Lee (2008). "A simple validated scale to measure urgency." J Urol 179(3): 1000-1005.

Anderson, G. G., J. J. Palermo, J. D. Schilling, R. Roth, J. Heuser and S. J. Hultgren (2003).

"Intracellular bacterial biofilm-like pods in urinary tract infections." Science 301(5629): 105-107.

Asma, B., L. Vicky, D. Stephanie, D. Yves, H. Amy and D. Sylvie (2018). "Standardised high dose versus low dose cranberry Proanthocyanidin extracts for the prevention of recurrent urinary tract infection in healthy women [PACCANN]: a double blind randomised controlled trial protocol." BMC Urol 18(1): 29.

Betschart, P., D. Abt, H. P. Schmid, P. Viktorin, J. Langenauer and V. Zumstein (2018). "Readability assessment of commonly used urological questionnaires." Investig Clin Urol 59(5): 297-304.

Bono, M. J. and W. C. Reygaert (2018). Urinary Tract Infection. StatPearls. Treasure Island (FL), StatPearls Publishing StatPearls Publishing LLC.

Collier, S., F. Matjiu, G. Jones, M. Harber and S. Hopkins (2013). "A prospective study comparing contamination rates between a novel mid-stream urine collection device (Peezy) and a standard method in renal patients." Journal of Clinical Pathology. 67(2): 139- 142.

Davies, E. M. and D. A. Lewis (2004). Bacteriology of urine. In: Hawkey P., Lewis DA., editors. Medical bacteriology Oxford. Oxford, Oxford University Press.

Dougherty, L., S. Lister and A. West-Oram (2015). The Royal Marsden Manual of Clinical Nursing Procedures (Royal Marsden Manual Series). West Sussex, Wiley Blackwell.

Dukes, C. (1928). "Some Observations on Pyuria." Proc R Soc Med 21(7): 1179-1183.

Flores-Mireles, A. L., J. N. Walker, M. Caparon and S. J. Hultgren (2015). "Urinary tract infections: epidemiology, mechanisms of infection and treatment options." Nat Rev Microbiol 13(5): 269-284.

Gill, K., R. Kang, S. Sathiananthamoorthy, R. Khasriya and J. Malone-Lee (2018). "A blinded observational cohort study of the microbiological ecology associated with pyuria and overactive bladder symptoms." Int Urogynecol J.

Hallstrom, K. A., K. O. Hallstrom, P. Gronroos and R. Ruosteenoja (1975). "Uriglox and quantitative urine microscopy in diagnosis of urinary tract infection." Acta Med Scand 198(6): 497-503. 
Haylen, B., D. De Ridder, R. M. Freeman and e. al. (2010). "An International Urogynecological Association (IUGA)/International Continence Society (ICS) joint report on the terminology for female pelvic floor dysfunction." Neurourol Urodyn 29: 4- 10.

Hiraoka, M., Y. Hida, S. Tuchida, H. Tsukahara, M. Yamashita, M. Kuroda and M. Sudo (1993). "Diagnosis of urinary tract infection by urine microscopy using a disposable counting chamber." Scand J Clin Lab Invest 53(7): 705-709.

Horsley, H., J. Malone-Lee, D. Holland, M. Tuz, A. Hibbert, M. Kelsey, A. Kupelian and J. L. Rohn (2013). "Enterococcus faecalis subverts and invades the host urothelium in patients with chronic urinary tract infection." Plos One 8(12).

Huysal, K., Y. U. Budak, A. U. Karaca, M. Aydos, S. Kahvecioglu, M. Bulut and M. Polat (2013). "Diagnostic accuracy of uriSed automated urine microscopic sediment analyzer and dipstick parameters in predicting urine culture test results." Biochem Med (Zagreb) 23(2): 211-217.

Jackson, S., J. Donovan, S. Brookes, S. Eckford, L. Swithinbank and P. Abrams (1996). "The Bristol Female Lower Urinary Tract Symptoms questionnaire: development and psychometric testing." $\underline{\mathrm{Br} J}$ Urol 77(6): 805-812.

Kashef, N., G. E. Djavid and S. Shahbazi (2010). "Antimicrobial susceptibility patterns of communityacquired uropathogens in Tehran, Iran." J Infect Dev Ctries 4(4): 202-206.

Khasriya, R., S. Khan, R. Lunawat, S. Bishara, J. Bignall, M. Malone-Lee, H. Ishii, D. O'Connor, M. Kelsey and J. Malone-Lee (2010). "The inadequacy of urinary dipstick and microscopy as surrogate markers of urinary tract infection in urological outpatients with lower urinary tract symptoms without acute frequency and dysuria." J Urol 183(5): 1843-1847.

Khasriya, R., S. Sathiananthamoorthy, S. Ismail, M. Kelsey, M. Wilson, J. L. Rohn and J. Malone-Lee (2013). "Spectrum of bacterial colonization associated with urothelial cells from patients with chronic lower urinary tract symptoms." J.Clin Microbiol. 51(7): 2054-2062.

Lee, B. S., T. Bhuta, J. M. Simpson and J. C. Craig (2012). "Methenamine hippurate for preventing urinary tract infections." Cochrane Database Syst Rev 10: Cd003265.

Mysorekar, I. U. and S. J. Hultgren (2006). "Mechanisms of uropathogenic Escherichia coli persistence and eradication from the urinary tract." Proc Natl Acad Sci U S A 103(38): 14170-14175. 
NICE (2013). Urinary Tract Infection (Women)- Lower, National Institute for Health and Care Excellence.

Nik-Ahd, F., A. Lenore Ackerman and J. Anger (2018). "Recurrent Urinary Tract Infections in Females and the Overlap with Overactive Bladder." Curr Urol Rep 19(11): 94.

Okragla, E., K. Szychowska and L. Wolska (2014). "Mechanisms of urinary tract sterility maintenance." Postepy Hig Med Dosw (Online) 68(0): 684-694.

Panek, J., H. El Alaoui, A. Mone, S. Urbach, E. Demettre, C. Texier, C. Brun, A. Zanzoni, E. Peyretaillade, N. Parisot, E. Lerat, P. Peyret, F. Delbac and D. G. Biron (2014). "Hijacking of Host Cellular Functions by an Intracellular Parasite, the Microsporidian Anncaliia algerae." PLoS One 9(6): e100791.

Pappas, P. G. (1991). "Laboratory in the Diagnosis and Management of Urinary Tract Infections." Med Clin N Am 75(2): 313- 325.

Patel, A. K. and C. R. Chapple (2008). "Anatomy of the lower urinary tract." Surgery (Oxford) 26(4): 127-132.

Raza-Khan, F., K. Kenton, S. Shott and L. Brubaker (2006). "Usefulness of urine dipstick in an urogynecologic population." Int Urogynecol J Pelvic Floor Dysfunct 17(5): 489-491.

Reigstad, C. S., S. J. Hultgren and J. I. Gordon (2007). "Functional genomic studies of uropathogenic Escherichia coli and host urothelial cells when intracellular bacterial communities are assembled." ․ Biol Chem 282(29): 21259-21267.

Robinson, D., I. Giarenis and L. Cardozo (2015). "The management of urinary tract infections in octogenarian women." Maturitas 81(3): 343-347.

Rosen, J. M. and D. J. Klumpp (2014). "Mechanisms of pain from urinary tract infection." Int J Urol 21 Suppl 1: 26-32.

Sorrentino, F., R. Cartwright, G. A. Digesu, L. Tolton, L. Franklin, A. Singh, P. Greco and V. Khullar (2014). "Associations between individual lower urinary tract symptoms and bacteriuria in random urine samples in women." Neurourology Urodynamics 34(5): 429 - 433. 
Swamy, S., W. Barcella, M. De Iorio, K. Gill, R. Khasriya, A. S. Kupelian, J. L. Rohn and J. Malone-Lee (2018). "Recalcitrant chronic bladder pain and recurrent cystitis but negative urinalysis: What should we do?" Int Urogynecol J 29(7): 1035-1043.

Turner, L. C., R. Beigi, J. P. Shepherd and J. L. Lowder (2014). "Utility of dipstick urinalysis in peri- and postmenopausal women with irritative bladder symptoms." Int Urogynecol J 25(4): 493-497.

Vickers, D., T. Ahmad and M. G. Coulthard (1991). "Diagnosis of urinary tract infection in children: fresh urine microscopy or culture?" Lancet 338(8770): 767-770.

Wagner, T. H., D. L. Patrick, T. G. Bavendam, M. L. Martin and D. P. Buesching (1996). "Quality of life of persons with urinary incontinence: development of a new measure." Urology 47(1): 67-71; discussion 71-62.

Watson, R. (2011). Anatomy and Physiology for Nurses: With Pageburst access, Bailliere Tindall. Yeoh, M., N. K. Lai, D. Anderson and V. Appadurai (2013). "Macroscopic haematuria--a urological approach." Aust Fam Physician 42(3): 123-126. 